P41 STRIBILD ${ }^{\text {TM }}$ (EMTRICITABINE/TENOFOVIR/ELVITEGRAVIR/ COBICISTAT) AND DARUNAVIR: A NOVEL REGIMEN FOR THE PI EXPERIENCED, RITONAVIR INTOLERANT PATIENT

Matthew Page*, Sarah Barrett, Steve Taylor. Heartlands Hospital NHS Foundation Trust, Birmingham, UK

10.1136/sextrans-2015-052126.85

Case report We present the case of a $42 \mathrm{yr}$ old female, diagnosed with HIV in 1992, presenting on a failing PI and integrase inhibitor based antiretroviral (ARV) regimen. She was intolerant to ritonavir, had significant drug resistance and poor adherence, but achieved virological suppression using the novel combination of Stribild ${ }^{\mathrm{TM}}$ [elvitegravir (EVG)/cobicistat/tenofovir (TDF)/emtricitabine (FTC)] and darunavir (DRV). She had been on multiple ARV combinations since 1994, including NRTI mono-therapy. Medication intolerance, non-adherence and stopping ARVs against advice, had led to HIV drug resistance. Her regimen comprised raltegravir (RAL), DRV, RTV and TDF. Due to her intolerance to RTV, she took this sporadically. This resulted in viral rebound from $<40 \mathrm{c} / \mathrm{ml}$ to $5,483 \mathrm{c} / \mathrm{ml}$. Cumulative resistance assays demonstrated NRTI, NNRTI and protease inhibitor mutations. Her virus was $\mathrm{X} 4$ tropic, but remained sensitive to integrase inhibitors.

To combat this issue a novel approach using Stribild ${ }^{\mathrm{TM}}$ with DRV 1200 mg OD was started, taking into account the patient's resistance profile and RTV intolerance. Due to minimal pharmacokinetic (PK) studies of this combination, and the potential for suboptimal and/or altered PK of cobisistat, EVG and DRV, therapeutic drug monitoring was utilised. Adherence was monitored using MEMs $\mathrm{CAP}^{\mathrm{TM}}$, which showed excellent adherence. Trough drug concentrations at $23 \mathrm{hrs}$ post-dose were $2692 \mathrm{ng} / \mathrm{ml}$ for DRV and 1,155 ng/ml for EVG. Subsequently, she achieved rapid virological suppression, asymptomatically.

Discussion/conclusion Issues of drug intolerance and resistance can be a therapeutic dilemma. We present the first case study using the regimen of Stribild ${ }^{\mathrm{TM}} / \mathrm{DRV}$, utilising cobi to enhance DRV concentrations. This well tolerated salvage regimen may be an option for some individuals.

\section{P42 THE FORENSIC SIGNIFICANCE OF STI'S}

Deb Wardle*. Archway Sarc, C/o Sandyford Sexual Health Services, Glasgow, UK

\subsection{6/sextrans-2015-052126.86}

Background/introduction Testing for STI's following sexual assault is routine. In cases were there is no other sexual activity other than the sexual assault, the assailant may be the source, and a positive result of significance in criminal investigation.

Aim(s)/objectives The potential forensic significance of STI results should be considered in each case.

Methods Discussion on information sharing of STI results is undertaken in cases referred to a sexual assault referral centre (SARC) with an absence of other sexual activity. This is documented and includes interpretation of results.

Case 1: An adolescent female, not previous sexually activity, vaginally raped, had a bacterial STI screen and serum save taken hours after the assault. Genital discomfort subsequently developed. A presumptive diagnosis of genital herpes made and tested. Herpes antibody testing was requested on samples taken; initially, when symptomatic and post symptoms.
Case 2: An elderly female, widowed several years earlier and sexually inactive since was vaginally raped. A bacterial STI screen was taken at the time initially and 14 days later.

Results Case 1 - HSV Type 2 confirmed. HSV antibodies initially absent were demonstrated in the post symptomatic sample. Case 2 - Initial Chlamydia trachomatis NAAT tested negative with a positive result at 2 weeks.

Discussion/conclusion The results are supportive of the assailants as the source. The positive Chlamydia result supported the penile vaginal penetration described, allowing consideration of a rape charge rather than a lesser offence. In both cases admissions were made pre-trial avoiding victims being called to court.

\section{P43 DON'T FORGET TO CHECK FOR STIS.... A REPORT ABOUT GONORRHOEA PROCTITIS BEING MISTAKEN FOR A FLARE-UP OF CROHN'S DISEASE}

Durba Raha*. Chalmers Centre, Edinburgh, UK

10.1136/sextrans-2015-052126.87

Background/introduction STIs are not routinely tested for in hospital which means they are often missed when they are an important differential diagnosis.

Aim(s)/objectives To present a case of rectal gonorrhoea (GC) in a patient with well-controlled Crohn's disease (CD) who presented to gastroenterology before diagnosis of GC in GUM.

Methods Case report and literature review.

Case report A 37 year old man presented to gastroenterology with diarrhoea, abdominal pain, proctalgia and tenesmus. He was known to have $\mathrm{CD}$ which had been in remission with treatment. X-ray showed faecal impaction and he commenced laxatives. Bowels regularised but remained painful. $\mathrm{He}$ was discharged with topical diltiazem, lidocaine gel and Metronidazole. At follow up he reported continuing proctalgia and small amounts of rectal bleeding. Exploration under anaesthesia revealed a peri-anal fissure and a sinus which was de-roofed and treated with local anaesthetic. MRI showed an inflamed anal gland. Colonoscopy, biopsies and stool cultures were normal. $\mathrm{He}$ then attended sexual health as he recently found out his regular male partner had been unfaithful. Proctoscopy was painful and revealed discharge and inflamed anal mucosa. On microscopy $>$ 10 neutrophils per high powered field were seen with a mixture of gram positive and negative organisms. Proctitis was treated with Doxycycline. Rectal GC tests were positive and this was treated. At test of cure symptoms had resolved and have not recurred since.

Discussion/conclusion Literature search reveals publications from recent years about STIs being initially misdiagnosed in hospital. This case further highlights the importance of asking routinely about partners in patients with bowel symptoms.

\section{P44 RPR-NEGATIVE PRIMARY SYPHILIS IN MEN WHO HAVE SEX WITH MEN: A CASE SERIES}

${ }^{1}$ Mark Papp*, ${ }^{2}$ Bavithra Nathan. 'St. George's, University of London, London, UK; ${ }^{2}$ Kingston Hospital NHS Foundation Trust, London, UK

\subsection{6/sextrans-2015-052126.88}

Background/introduction Diagnosis of primary syphilis is confirmed by serological tests suggestive of the stage of the disease. In most cases specific (IgM/IgG) and non-specific (RPR) 
antibodies develop in response to primary treponemal infection. Lack of development of such antibodies is known to occur amongst HIV positive patients but is unusual among HIV negative patients with no significant comorbidities.

Aim(s)/objectives To present a cluster of four cases of primary syphilis from our clinic with unexpected serological results.

Methods We describe four unusual cases of HIV-negative MSM, all of whom presented with penile lesions (three chancres and an atypical lesion). These cases were identified by clinicians between July 2014 and January 2015. Clinical and laboratory records were retrospectively interrogated. Clinical photographs will be used to illustrate these cases.

Results In all cases, patients with no history of previous syphilis returned positive results on one or more specific treponemal serological tests with persistently negative RPR. Three cases had recent negative syphilis screening at our clinic. Darkfield microscopy also failed to demonstrate T. pallidum in those with chancres. In all cases, treatment of presumed syphilis led to the resolution of the lesions.

Discussion/conclusion These cases demonstrate the ongoing difficulties with treponemal diagnostic test interpretation. There are reports in the literature that men over 35 may be more likely to return a false negative RPR result, but overall prevalence of false negative RPR in primary syphilis is uncertain. Over-reliance on serology may result in under diagnosis of syphilis even in HIV-negative MSM.

\section{P45 RECALCITRANT TRICHOMONAS VAGINALIS; A CASE SERIES OF TREATMENT CHALLENGES AT TWO URBAN SITES}

${ }^{1}$ Lauren Bull ${ }^{*},{ }^{2}$ Brenton Wait, ${ }^{1}$ Sara Day, ${ }^{2}$ Sarah Creighton, ${ }^{1}$ Michael Rayment. ${ }^{1}$ Chelsea \& Westminster Hospital, London, UK; ${ }^{2}$ Homerton University Hospital, London, UK

\subsection{6/sextrans-2015-052126.89}

Background/introduction Trichomonas vaginalis (TV) remains common in England, with 6475 cases reported in 2013. BASHH guidelines ${ }^{2}$ advocate first line TV treatment with metronidazole (2 g stat or $400 \mathrm{mg}$ BD for five to seven days) or a single dose of tinidazole $(2 \mathrm{~g})$. Recalcitrant infections have been well documented and may be caused by inadequate therapy, reinfection or antibiotic resistance. ${ }^{3}$ In the US, up to $5 \%$ of isolates of TV demonstrate a degree of resistance. ${ }^{4}$ In the UK there remains no facility to test for TV resistance, leading to multiple 'blind' treatment approaches. We wished to evaluate the prevalence and clinical management of recalcitrant TV in our services. Methods Clinic databases were used to identify patients with recalcitrant TV attending two sexual health services over a two year period.

Results A total of 1046 cases of TV were seen across the two services in the study period. Four female patients $(0.4 \%)$ with recalcitrant TV requiring three or more treatments were identified. The patients were aged between aged 25 and 47 years. Two were black British, one white British and one white European. All four patients failed to respond to at least two five day courses of metronidazole; they required between three and eleven different courses of treatment, as per the table below:

During the courses of treatment all four patients were microscopy and culture negative at least once. However, symptoms persisted and tests were subsequently positive on at least one other occasion, despite no risk of reinfection. Three patients subsequently responded to fourteen days of tinidazole and one required acetarsol treatment. Three were eventually cured of TV, taking between 3-7 months to achieve cure and 5 and 12 clinic visits; one was lost to follow up, presumed cured.

Discussion Recalcitrant TV is rare, but for patients affected, the absence of a UK facility to detect TV resistance means that individuals who fail to respond to first line therapy undergo multiple attempts at TV treatment, recurrent clinic visits and investigations.

\section{P46 THE MANAGEMENT OF ABNORMAL LFTS IN AN HIV POSITIVE PREGNANT WOMAN}

${ }^{1}$ Gillian Fraser*, ${ }^{1}$ Andrew Winter, ${ }^{2}$ Roch Cantwell, ${ }^{3}$ Helen Mactier, ${ }^{3}$ Elizabeth Ellis. ${ }^{1}$ Brownlee Centre, Gartnavel General Hospital, NHS GG\&C, Glasgow, UK; ${ }^{2}$ Perinatal Mental Health Service, Leverndale Hospital, NHS GG\&C, Glasgow, UK; ${ }^{3}$ Princess Royal Maternity Hospital, NHS GG\&C, Glasgow, UK

\subsection{6/sextrans-2015-052126.90}

Background Acutely deranged liver function tests (LFTs) in HIV positive pregnant women present challenges in balancing pregnancy-related conditions, antiretroviral (ARVs) toxicities and prevention of mother to child transmission (MTCT). A 34 year old HIV positive lady with a history of poor engagement in care, psychosis, cognitive impairment and recent nevirapine resistance

\begin{tabular}{|c|c|c|c|c|c|}
\hline & Ethnicity & Age & $\begin{array}{l}\text { First line } \\
\text { treatment }\end{array}$ & Subsequent treatments & Time to clinical cure \\
\hline 1 & White European & 28 & $\begin{array}{l}\text { MTZ } 400 \mathrm{mg} \mathrm{BD} \\
5 \text { days }\end{array}$ & MTZ $400 \mathrm{mg}$ BD 5 days; TDZ $2 \mathrm{~g}$ OD 14 days & 4 months (5 clinic visits) \\
\hline 2 & Black British & 47 & $\begin{array}{l}\text { MTZ } 400 \mathrm{mg} \mathrm{BD} \\
5 \text { days }\end{array}$ & $\begin{array}{l}\text { MTZ } 400 \text { mg BD } 5 \text { days X3 ( } 2 \text { in community); MTZ } 400 \text { mg BD } 5 \text { day amoxicillin } \\
500 \text { mg TDS + clotrimazole pessary, } \\
\text { TDZ } 2 \text { g STAT, TDZ } 2 \text { g BD } 14 \text { days }\end{array}$ & $\begin{array}{l}2 \text { months-Lost to follow-up } \\
\text { ( } 5 \text { clinic visits) }\end{array}$ \\
\hline 3 & White British & 29 & $\begin{array}{l}\text { MTZ } 400 \mathrm{mg} \mathrm{BD} \\
5 \text { days }\end{array}$ & $\begin{array}{l}\text { MTZ } 400 \mathrm{mg} \text { BD } 5 \text { days } \times 3 \text {; } \\
\text { Amoxicillin } 500 \mathrm{mg} \text { TDS } 7 \text { days+clotrimazole pessary + MTZ } 400 \mathrm{mg} \text { BD } 5 \text { days, } \\
\text { TDZ } 2 \mathrm{~g} \text { OD for } 14 \text { days }\end{array}$ & 3 months (6 clinic visits) \\
\hline 4 & Black British & 25 & $\begin{array}{l}\text { MTZ } 400 \mathrm{mg} \mathrm{BD} \\
5 \text { days }\end{array}$ & $\begin{array}{l}\text { MTZ } 400 \mathrm{mg} \text { BD } 5 \text { days } \times \text { 3; } \\
\text { Amoxicillin } 500 \mathrm{mg} \text { BD } 7 \text { days + MTZ } 400 \text { TDS } 7 \text { days; MTZ } 1 \mathrm{~g} \text { suppositories } \\
7 \text { days + amoxicillin } 500 \mathrm{mg} \text { TDS } 7 \text { days, MTZ } 2 \mathrm{~g} \text { OD } 5 \text { days; TDZ } 2 \mathrm{~g} \text { OD for } \\
14 \text { days; MTZ } 400 \mathrm{mg} \text { TDS }+1 \text { g PR } 7 \text { days; } \\
\text { TDZ } 2 \text { g BD } 14 \text { days + TDZ } 500 \text { mg BD PV x2 courses; Acetarsol } 500 \mathrm{mg} \text { pessaries ON } 14 \text { days }\end{array}$ & 6 months (12 clinic visits) \\
\hline
\end{tabular}

